\title{
METHODOLOGICAL BASES OF VOCATIONAL EDUCATION (AS EXEMPLIFIED BY TRAINING RAILWAY SPECIALISTS)
}

\author{
Malaniuk Nataliia ${ }^{1}$ \\ Romanyshyna Ludmila ${ }^{2}$
}

DOI: dx.doi.org/10.30525/978-9934-571-30-5_29

\begin{abstract}
The article outlines the methodological basis for the reform of higher professional education (as exemplified by training of railway specialists). The subject of the study is higher professional education. The purpose of the study is theoretical substantiation and practical implementation of methodological approaches to the construction of updated higher professional education, in accordance with the needs of modern society. Such methodological approaches as: competence, synergetic, acmeological have been described. The opportunities presented by each of the approaches considered for the improvement of higher professional education are revealed. The use of a competent approach to the system of higher vocational education provides a qualitative basis for the formation of a professional (competent) professional who has professional competence. The application of the ideas of the competence approach in higher professional education changes the purpose and the result of educational activity: from the accumulation of the amount of disparate knowledge, skills, skills for the formation of future specialists ability to creatively act in non-standard production situations, using the experience gained during the training period. The role of the teacher will also change: from the relay of knowledge of a skilled mentor and the organizer. The leading activity of the student is also changing: from the passive "listener" he becomes an active "researcher". The competence approach in the system of higher vocational education performs the following functions: is a methodological one, prescribed in the Laws of Ukraine ("On Education", "On Higher Education", etc.); creates conditions for the approximation of the national education to the European one; called to change the educational paradigm to a one that meets the modern requirements of society;
\end{abstract}

\footnotetext{
${ }^{1}$ Candidate of Pedagogical Sciences, Lecturer of Mathematics, Kyiv College of Transport Infrastructure, Ukraine

${ }^{2}$ Doctor of Pedagogical Sciences, Professor, Head of the Department of Pedagogy, Khmelnytskyi Humanitarian-Pedagogical Academy, Ukraine 
provides a reference point for education on the outcome. Education is not a constant (constant, unchanged), it is constantly evolving and undergoing change under the influence of external factors and its own laws of "evolution". The theory of synergetics in education points out that humanity (society of knowledge) has to take care of its "preservation", but also about perfection and development (self-improvement, self-development). Humanity without education (out of education) can not develop (to move from one state to another: from passivity to activity; from reproduction to creativity; from consumption to creativity). Implementation of the synergetic approach to higher professional education contributes to the improvement of the quality of education, since: it allows a new way to resolve the contradictions of today's pedagogical science, the key concepts of which are the following characteristics: constancy / variability, predictability / randomness, individual / collective, chaos / structuring, etc.; changes the educational vector for the unification of knowledge into the formation of a creative person; Provides new opportunities in the educational process (individual trajectories of development and self-development of all participants in the educational process); promotes the solution of didactic problems (compliance of the content of education with the requirements of time, selection of technological and methodological approaches, etc.). Acmeology, its central determinant, is the state of the person, in which it achieves the highest result in activity (and professional). Since the tasks of a modern vocational school are the formation of a specialist professional, therefore acmeological factors and factors should be taken into account in the educational process. Our studies have shown that, based on acmeology as a methodological basis, vocational education needs to form a clearly defined motivational component, since motivation is a driving force for success in any activity. The introduction of the acmeological approach in the system of higher vocational education will provide the following possibilities: modernization of higher professional education; development of the best qualities of each student, disclosure of his creative potential; improvement of the quality of higher professional education; formation of the image (prestige) of a specialty; formation of the image of the graduate (his self-realization, professional identity).

\section{Introduction}

The second decade of the twenty-first century was marked by global integration and transforming processes both in Ukraine and abroad. These pro- 
cesses directly or indirectly relate to all spheres of human activity (including education). The European integration processes taking place in Ukraine put forward new requirements for the educational (professional) training of a young person. The key to today's specialist is not the availability of "paperwork" of his professional readiness (matching the chosen position), but the skills and experience gained during the learning process at various levels of continuing vocational education. The defining feature of the 21 st century specialist is professional competence (professional identity, professional self-determination - I am the concept of a future specialist), which creates conditions for competitiveness in the world labour market (decent wages of satisfaction from work self-realization of satisfaction from life).

Thus, the problem of the inconsistency of higher education with the needs of each individual is acute. The need for reforming the system of higher education in general is urgent. In the context of our study, we will focus on the urgent need to reform the system of training a specialist in railway transport in the "College-University" system.

The aim of our study is to provide theoretical substantiation and experimental verification of methodological approaches to building upgraded higher professional education in accordance with the needs of modern society.

To implement the reform of higher education successfully, you need:

- to define the conceptual bases of the new higher school, which is designed to meet the modern needs of each person (student of college, university);

- construction of the newest educational models in the light of European integration processes and rapid scientific and technological progress;

- Implementation of the latest educational models in the practical activities of higher education institutions (systematic testing and improvement, a proactive function - forecasting the development of the industry for 10-50 years).

The modern system of education is characterized by "falling into extremes": taking one scientific approach is completely discarded by others. We believe that in order to build an effective model of the system of vocational education it is necessary to use the synthesis of the advantages of each scientific approach. Let's dwell on the following approaches: competence, synergetic, acmeological. We will analyze the advantages and opportunities of applying each approach to reforming higher professional 
education, and also consider the problems that arise when implementing these approaches in the system of vocational education.

Competence approach

Competence approach in the system of education (higher education) came to replace the "know how" approach in the post-Soviet period, although it began to form in the 1960s. The reasons for the decline of the traditional ("knowledge") approach:

- a large amount of scientific information that a person is physically unable to process or remember;

- variability of information;

- rapid pace of development of science and technology.

Researchers I. Burhun and T. Krystopchuk point out the external and internal factors that influenced the introduction of the competence approach in education in Ukraine, determining its relevance:

- external:

1. The rapid social, economic, political development of the world, which sets new requirements for graduates of higher education institutions (flexibility, mobility, creativity, responsibility, efficiency, etc.).

2. Ukraine's accession to the Bologna process (development of common standards for Ukraine and Europe based on the competence approach).

3. Global computerization (information filtering and searching).

- internal:

1. Change the phenomenon of "knowledge".

2. Loss of need to overload memory $[4 ; 11]$.

The competence approach as a methodological basis for the unity of purpose, content and quality of higher education has become the subject of research by such Ukrainian scholars as N. Bibik, O. Hulai, O. Dubaseniuk, O. Lokshyna, O. Ovcharuk,.I. Malafiika, O. Pometun, L. Romanyshyna, S. Trubachova and others. Among the foreign scholars who contributed to the theory and practice of the competence approach are V. Baidenko, A. Bermus, I. Zimnia, M. Leiter, J. Raven, H. Selevko, V. Serikov, E. Toffler, A. Khutorskoi and others.

The scientist I. Zymnia [6] points out three key stages of the formation and development of the competence approach in education in general. So the first stage $-60-70$-ies of the twentieth century was marked by the involvement in the scientific conceptual apparatus of the definition of "competence", as well as contributed to the creation of a basis for distinguishing the concepts of 
"competence" and "competence". The second stage is the 70-90s of the twentieth century. was characterized by the active practical use of the definitions of "competence" and "competence" for the study of philologists (language, communication), as well as for the characterization of professional activities of specialists in the fields of management, management, management. The third stage - the 90 s of the last century - and continues today, because "competence" and "competence" are prescribed in the basic laws "On Education", "On Higher Education" as a goal and as a result of the educational activities of educational institutions of different levels of accreditation.

The need to apply the competence approach in education is a response to today's demands - a change in the educational paradigm that should meet the demands of all participants in the educational process and the labour market, taking into account the globalization and integration of world and European trends of the present. The main task of this approach is to develop the ability of students to actively apply successful theoretical and practical experience in their professional activities, possessing not just theoretical knowledge, but their ability to apply them in a variety of industrial situations. The problem of the competence approach in the light of higher education is a specific interpretation: it is not just a system that allows a fairly objective assessment of the suitability of each individual graduate for future activities, as well as to develop clear criteria for assessing this quality, allowing future employees to carry out targeted training for obtaining required certificate and recognition in this area [3].

The scientist O. Zhuk [5] defined the following functions of the competence approach in education:

- operational - identification of the system of knowledge, skills and abilities, various activities of the student, which will be crucial for the formation of his competence and will contribute to the effective resolution of professional, personal and social tasks;

- activity-technological - ensuring the construction of the content of training, as close as possible to the future scope of the contender, the development and implementation of tasks in the educational process, methods of solving which correspond to the technologies of vocational education;

- educational - strengthening of the educational component of the educational process, the acquisition of experience by students (organizational, management, etc.), the formation of a culture of personal and professional communication; 
- diagnostic - development of a more effective system for monitoring the quality of educational and professional process, including diagnostics of the achieved levels of formation of competence (and competencies).

The researcher H. Selevko [20, p. 138-143] notes that the competence approach implies a gradual reorientation of the leading educational paradigm with a dominant translation of knowledge and the formation of skills in such a way that it will help create the conditions for acquiring a system of competencies that will guarantee the potential, ability graduate to survival and active professional activity in the modern conditions of multifactorial socio-political, market-economic, informational and communication life space.

Key definitions of the competence approach are "competency" and "competence". Scientists are still unanimous in the interpretation of these concepts and relations between them. For example, the European Centre for the Development of Vocational Education (CEDEFOP) expresses the following considerations regarding this issue: "There is such confusion and sharp discussion of the concept of" competency / competence "that it is impossible to identify or assign to someone a consistent theory or to reach a definition that is capable of adapting and reconciling all different ways to use the term. This terminological confusion often reflects the mixing of various concepts and the inconsistent use of terms" [25, p. 53].

We share A. Khutorskoi's opinion of concerning the relation between the concepts of "competency" / "competence": competency - a set of interdependent qualities of the individual (knowledge, skills, skills, methods of action), which are asked in relation to a certain range of subjects and processes and necessary to act qualitatively and productively. in relation to them; competence - the possession of a person with a set of relevant competences, including its personal attitude to them and the subject of activity $[23$, p. 58-64.]. The author believes that the competence - alienated, the social requirement (norm) for the education of the person who is studying is necessary for his qualitative productive activity in a certain field, and competence is an individual-psychological feature, mastery, possession of the relevant competence, which contains the personal attitude of the student (student) to her and the subject of activity [24].

Scientist Y. Stelmakh, the follower of the ideas of L. Millrud, is convinced that "competence can be regarded as a complex of competencies that are determined by a set of interrelated qualities of personality, necessary for 


\section{Chapter 13. Pedagogical sciences}

productive productive activity in relation to a certain range of objects and processes" [21, p. 4].

Scientist J. Raven thinks that competence is a certain specific ability of a person, which is necessary for effective (qualitative) performance of a certain type of activity in a particular sphere of human life. The author also points out that the above described ability already involves the presence of a person (student, college graduate) general and narrow special knowledge, specific subject skills, ways of thinking, responsibility for their actions $[18$, p. 6].

The introduction of a competent approach to the system of education (higher education) changes the purpose and the result of educational activities: from the accumulation of the amount of disparate knowledge, skills, skills for the formation of future specialists the ability to creatively act in non-standard production situations, using the experience gained during the training period. The role of the teacher is also changing: from the relay of knowledge of a skilful mentor and the organizer. The leading activity of the student is also changing: from the passive "listener" he becomes an active "researcher".

We agree with the opinions of most scholars on the problem of modern higher education - not to equip the graduate with the amount of professional knowledge, but to prepare a specialist who can apply the acquired knowledge in practical activities, who understands his place and role in a society capable of learning in accordance with the new requirements of professional activity, to take independently make production decisions and be responsible for them [19]. The basis for these tasks is the competence approach in education, which today plays a leading role in the methodology of education, since it enables the education to meet the demands of modern society in the context of European integration processes, knowledge mobility and the labor market.

According to O. Hodan [22, p. 233], "the general idea of competence is the competence-oriented education, which aims at the complex acquisition of knowledge and methods of practical activity, through which a person successfully implements himself in various fields of his life."

Implementation of the competence approach in the system of higher education (in particular, professional) provides a qualitative basis for the formation of a professional (competent) professional who has professional competence. Scientist L. Elahina [7, p. 23] emphasizes that it is the com- 
petence approach that allows "to select the content of vocational education in accordance with the needs of the individual and at the same time orient it to successful innovative experience in the professional activity in each particular field".

At the same time, there are a number of problems associated with the application of the competence approach in the system of higher vocational education:

1. Students' unpreparedness for independent work (experience of school education, often rural, is reduced to explanatory, illustrative, relaying).

2. The reluctance of teachers to change methods and approaches to work with students (work 10 years ago, 20 years ago, etc.).

3. Lack of proper material and technical support of the educational institution.

4. Inadequate connection between different levels of continuing education in the "college-university" system.

5. Low level of cooperation between institutions of vocational education and production (practice, further employment of graduates).

6. Lack of building an image, prestige of specialties.

You can solve these problems as follows:

1. Formation of the motivational component of the activity of students of freshmen, the culture of educational activity, independence.

2. Realistic training courses for teachers (seminars, trainings, master classes).

3. Cooperation of educational institutions.

4. Harmonization of curricula and programs of institutions of different levels of accreditation.

5. The interest of employers in professional staff, subsidies from the state for training and placement of graduates without work experience.

6. At the state level, as well as in educational institutions, creating an image, prestige of specialties (from the first days of college education).

Implementation of the competence approach in education as a basis for the modernization of education in general is designed to solve the following tasks:

- updating the standards of higher education (education programmes in accordance with accepted in European countries);

- construction of a model of a graduate of a new generation (having a professional competence); 
- construction of a holistic system of continuous vocational education that meets the contemporary demands of society.

Conclusions:

1. The competence approach in today's education is methodological, since it is prescribed in the Laws of Ukraine ("On Education", "On Higher Education", etc.).

2. The competence approach in vocational education creates conditions for the approximation of the national education to the European one.

3 . The competence approach is intended to change the educational paradigm to one that meets the contemporary challenges of society.

4. The competence approach provides a reference point for education on the result.

\section{Synergistic approach}

The second decade of the 21 st century is marked by the constant creative search for methodological approaches in education that could describe individual processes and phenomena that are of interest to both theoretical researchers and practitioners, whose purpose is to improve and improve existing educational processes, and who can build and explore strategies for their development.

Continuous vocational education in modern conditions does not correspond to public inquiries, since in the time of rapid economic changes it remains sedentary with little pronounced dynamism. Rapid scientific and technological progress, global eurointegration processes place essentially new demands on specialists (educators). There are constant creative searches of scholars, teachers, psychologists, philosophers, whose goal is to improve the existing system of continuing vocational education and bring it to a qualitatively different level - compliance with the requirements of "space and time". To this end, methods and definitions of other sciences are borrowed and introduced into the pedagogical science, in order to thoroughly analyze and predict the strategies for the development of education in general (and professional education in particular), to characterize educational phenomena from different perspectives. In particular, synergetics is an interdisciplinary methodology, designed to give "new breath" to pedagogical science.

Opportunities of synergetics as "polydisciplinary" and "transdisciplinary" science are highlighted in the writings of O. Kniazeva and S. Kurdi- 
umov. The questions of synergetics in education are devoted to research by V. Kremen, V. Iliin, G. Malinetskyi, E. Moren and others.

Synergetics today provides additional "opportunities" for various sciences, including, for pedagogy: tools for analyzing the complex behavior of man and society; promotes understanding of the relatively simple principles of organization and self-organization of extremely complex entities (systems); description with the help of parameters of order or asymptotic picture of evolutionary processes [9, p. 55].

Education is not a constant (constant, unchanged), it is constantly evolving and undergoing change under the influence of external factors and its own laws of "evolution". Education is a "pedagogical system, in the center of which Man is a plurality of people; the way of functioning of this system-pedagogical activity" [16, p.13]. The theory of synergetics in education points out that humanity (society of knowledge) has to take care of its "preservation", but also about perfection and development (self-improvement, self-development). Humanity without education (out of education) can not develop (to move from one state to another: from passivity to activity; from reproduction to creativity; from consumption to creativity).

According to the synergetic approach, everything that happens in the world (phenomena, processes) is unpredictable, random, chaotic. The same applies to education. It, as a "nonlinear system", develops not clearly defined path (instability), but each time finds (randomly) one of many existing ones. Academician V. Kremen emphasizes that "the feature of the integrity of the essence of the educational process is continuous evolution, or self-development on the principles of self-organization" [10, p. 72].

In education (and pedagogical science), at the level of the world community, a large number of materials have been developed and collected, and not all of them can be described with the help of purely humanitarian sciences (pedagogy - humanitarian science). Therefore, scientists every time resort to active searches for the application of interdisciplinary and transdisciplinary methodologies. "The interdisciplinary and transdisciplinary nature of synergetics is manifested in the holistic-networked way of structuring reality. This approach was the result of an integration trend aimed at "erasing" the faces between individual sciences, their specialization in problems, and not subjects" [10, p. 127].

The synergetic paradigm, including the entire experience of natural sciences, mathematics and social sciences, is designed to form a creative per- 
sonality from each subject of the education system, which freely determines the scope of his activity, actively interacts with the world, thus responding to the needs of a modern man, a modern culture.

The peculiarities of culture at the present stage that influence the formation of a "picture of the world" inevitably provoke a situation where, so-called, the traditional system of education does not meet the demands of society. Information technologies that through all permeate all spheres of human activity, form in each individual a new type of thinking (creative), new activity (creative). Today's culture is characterized by contradictions: on the one hand, it is homogeneous (within the ethnic group, the people, etc.), on the other - heterogeneous (multicultural, multicultural). This fact leads to the fact that various subjects put forward different educational requirements. The notion of a single pedagogical practice is leveled off. Instead, a new format of certain freedom of educational choice arises, diametrically opposed pedagogical practices arise.

Conceptual apparatus of pedagogy is ambiguous: different authors interpret the same definitions in different ways. Therefore, there is a need to conduct scientific and pedagogical research in the light of synergetics.

In the past, the picture of the world was constant (relatively unchanged), it served as the basis for building and perceiving objective reality by all members of society. Rapid scientific and technological progress has violated this "stability" of the world picture. Today, possessing a number of knowledge, there is no guarantee that they will all be needed tomorrow. Man must prepare for the variability of the surrounding reality (in all spheres of life), respond promptly and "adapt" to new challenges of time. Therefore, the key task of synergy in pedagogy, which has its basic characteristics of variability, procedurality, movement, development, giving answers (indications) to the contemporary world community's requests, helps to bring education closer to a state in which it can answer as much as possible today's demands.

During the educational process, the process of producing new knowledge from the system of available knowledge takes place, therefore, through the prism of synergetics, the main task of pedagogy (education) is to "create conditions for obtaining synergies that would ensure the acquisition of new knowledge" ("synergy" - the aggregate interaction of several factors, the result of which is greater than that which can be obtained with the sum of individual components") [10, p. 170]. 


\section{Malaniuk Nataliia, Romanyshyna Ludmila}

Pedagogy today is characterized by a rejection of authoritarianism, the personality of the student (student), the development of his individual abilities (creative abilities) and satisfaction of his social queries are placed on the foreground. The synergetic concept is intended to contribute to the construction of a single picture of the world, but this process is infinitely continuing. "Education of the third millennium from a holistic, unified picture of the world selects individual fragments that make up various educational disciplines. Therefore, often students (as well as students) do not have a holistic formation of the picture of the world, their knowledge is fragmented, there is no ability to construct logical, clear causal relationships" [13]. If we consider the pedagogical system through the prism of synergetics, then its key characteristic will be nonlinearity (variedmonity, multi-facetedness). The principle of non-linearity of the development of the pedagogical system for all objects of this system is realized in different ways. The pedagogical system is an open system characterized by an unstable state, a dynamics of development, with diverse elements in significance (importance). In the past, the state of so-called equilibrium was considered to be ideal. Any other unstable state was considered negative. Today there is a completely different vision of instability: instability is considered a necessary and sufficient condition for the development of the system (and pedagogical). According to O. Kniazeva and S. Kurdiumov [8, p. 54], "only systems that are far from stability, systems in states of non-equilibrium, can spontaneously organize and develop". We are talking about processes of self-development and self-organization of systems. We support the opinions of scientists O. Kniazeva and S. Kurdiumov, because we believe that the stability of the educational system leads to its decline. The variability of external conditions (rapid development of science and technology, mobility of the labor market) are the driving force for the educational system (the system of continuous professional education in particular). If the educational system does not endeavor to meet the demands of the society and the challenges of the present, it will lose its urgency and demand. Since the determinant in the synergetic theory belongs to the "attractor" (which is close to the definition of the "goal"), such an "attractor" in any pedagogical system is the goal of education [10, p. 185].

Didactic aspects of adaptation of synergetics to the content of education (at all levels) are first realized through the correspondence of the content of 
teaching with the requirements of modern society. This means that in the foreground there should be a person (student / student-graduate-specialist), and the educational process in the system of continuous education should contribute to the development of the best qualities, the formation of professionalism, responding to the challenges that today puts the society in a rapidly scientific -technical and informational and economic development, mobility of labor resources and their fierce competition.

We will analyse the system of preparation of future specialists of railway transport through the prism of the synergetic approach in the conditions of continuous professional education. The described system is a pedagogical system, and, therefore, open and non-linear and one that self-organizing to mechanisms of self-organization include the separation of parameters of order, methods of their description, corresponding to a certain model) [10, p. 193]. The educational process of training trainers of railway transport on the conceptual principles of the synergetic approach allows, under certain conditions (pedagogical), to determine qualitatively successful combinations that can serve as parameters of the order or mechanisms for the search of these parameters [14, p. 339]. Today, within the pedagogical systems, there are a number of methodologies. The principle of openness of the system allows self-organization (self-development) of the system by different methodologies, when they organically complement each other, reveal pedagogical problems from "different angles". The principle of nonlinearity of the system determines the transforming processes in the system for the purpose of improvement, improvement (self-organization, self-development). Such a system is characterized by multiple variability, since there is a variety of conditions in the educational environment (space), which gives each participant a system of special opportunities for achieving his own success, ensuring the development of creative potential, and promoting his autonomy in decision-making [13].

Implementation of the educational process of training future specialists of railway transport in conditions of continuous education of the synergetic approach gives new opportunities:

- the trajectory of personal development of all participants in the educational process (students and teachers);

- development (self-development) of all potential abilities of each student - the future specialist; 
- formation of creative (creative) thinking;

- continuing education as a basis for "life-long learning" (self-education) [13].

We characterize the "attractor" of the system of training railway transport specialists in conditions of continuous education. The training of a competitive railway specialist in conditions of continuing vocational education, which has professional competence, is the "attractor" of the described system.

Conclusions:

1. Synergetics allows a new way to solve the contradictions of today's pedagogical science, key concepts of which are such characteristics: constancy / variability, predictability / randomness, individual / collective, chaos / structuring, etc.

2. Synergetics changes the educational vector of unification of knowledge into the formation of a creative person.

3. Synergetics provides new opportunities in the educational process (individual trajectories of development and self-development of all participants in the educational process).

4. Synergetics contributes to the solution of didactic problems (compliance of the content of education with the requirements of time, the selection of technological and methodological approaches, etc.).

\section{Acmeological approach}

Achievement of high professionalism - the ultimate goal of professional development of a specialist. And for its realization it is necessary to carry out educational and self-education measures (education through all life). In the light of the implementation of this socio-cultural vocation personality is important acmeology - the science of the laws of professional development in the context of the implementation of any activity at the highest professional level. Acme - (Greek - $\alpha \kappa \mu \eta \dot{)})$ - the highest point, the summit "somatic, physiological, psychological and social status of the individual, characterized by the maturity of its development, the achievement of the highest performance in activity, creativity" [2, p. 15].

"Akmeologiya - the science of the laws, conditions, factors and incentives that promote or impede the self-realization of the creative potential of mature people in the process of self-movement to the heights of professionalism and productivity and productivity of creative activity, embodied in 
socially significant products of culture, art, literature, science, technology, education, as well as in the man himself' $[12$, p. 12].

It is qualitative education (and self-education) is a necessary and sufficient condition for productive creative activity, on the basis of which will be formed those personality traits that will ensure the performance of future professional activities.

The period of maturity begins with an independent choice of future profession (social maturity) [12, p. 15]. Thus, vocational education in the system "college-university" is intended to promote the development of professional qualities of students - future professionals.

Education at a college (university) is significantly different from studying in a general education institution: firstly, organizational forms (lesson a couple, etc.); and secondly, the status of the subject of learning (the child is a mature person). Therefore, when organizing the activities of universities of different levels of accreditation, the acmeological approach should be taken into account.

Acmeology, due to its central determinant, is the state of the person, in which he achieves the highest result in activity (and professional). The formation of this science (as well as the appearance of the term) took place in the 20-30's of the twentieth century. The ideological basis of acmeology as a science is the works of F. Galton, V. Osvald, I. Pern.

The scientist N. Kuzmin distinguishes five periods in the development of acmeology:

1. Latent - the laying of historical, cultural, social, philosophical, scientific, practical, pedagogical prerequisites of isolation from the scientific knowledge of the sphere of knowledge about man.

2. Nomination - 1928 - the introduction of the term "acmeology".

3. Incubation - the typology of acmeology is built.

4. Organizational and methodological - the development of acmeological theory itself.

5. The beginning of the XXI century - the implementation of the philosophical substantiation of the subject of acmeology, its connection with other sciences [1, p. 44-45].

In the current conditions of Ukraine's integration into the European economic space, when the requirements for staffing and resource provision of various sectors of the national economy are increasing, the acmeological concepts of professional development become more and more relevant. So 
the scientist O. Dubasenyuk emphasizes that "acmeology carries out integrated researches of processes and methods of implementation by various specialists of professional activity, synthesizing for this achievement of other sciences about a person, first of all, philosophy, sociology, psychology, physiology, genetics and pedagogy [17, p. 15]. The author believes that only by applying acmeological technologies in the educational process, it is possible to form a highly professional specialist. Under acmeological technologies O. Dubaseniuk understands "the systematic way of organizing the process of development of a mature person, disclosing its creative potential, a gradual trajectory of achieving the vertices of professionalism" [17, p. 110].

Scientist T. Shanskova to the basic concepts of acmeology includes acmeological conditions and acmeological factors. Acmeological conditions are "significant circumstances on which the achievement of a high level of progressive development of a mature person and especially its professionalism" [17, p. 123] depends. According to T. Shanskova, the most important acmeological factors are the desire for self-realization, high personal standards, a high level of professional perception and thinking. The author believes that acmeological factors are the driving force and the main determinants of the process of becoming a professional.

Consider the system of training a future specialist in railway transport from the point of view of the acmeological approach. Since the tasks of a modern vocational school are the formation of a professional specialist, therefore acmeological factors and factors should be taken into account in the educational process. With the beginning of studies at college (university), the social role of the young person, influencing her world perception, changes, becomes the basis of her life position. College teachers need to be prepared to help freshmen students master their new status, overcome the psychological barrier student-student, learn to make decisions themselves and bear responsibility for them, as well as a culture of learning activities (including self-help). To do this, it is advisable to use innovative and interactive teaching methods in the educational work (this applies not only to the freshmen). These methods will help students learn to express their opinions, substantiate their position, conduct a scientific discussion, and also experience the various roles associated with future professional activities. In order to achieve a high level of professionalism, the student must learn to set learning goals and achieve high academic results. 
Based on acmeology as a methodological basis, vocational education requires the formation of a well-defined motivational component, since motivation is the driving force for success in any activity. The image of the profession remains an important component of the motivation to engage in educational activities (and then professional ones). According to L. Danylchuk [15, p. 183], "the image represents a complex phenomenon of the present, which combines quite heterogeneous factors: historical, political, economic, social, personal, etc." We believe that all of the above factors should be taken into account in the process of research and the formation of the image (prestige) of a specialty. It is the image of the specialty, the desire to win the dream profession, to become the best in future professional activities - the driving force in achieving the acmeological goal of education - the formation of a specialist capable of achieving a high level of professionalism. Transformation processes taking place in Ukraine help to increase the image of specialists in transport specialties (in particular, railway transport). This is a visa-free regime between Ukraine and European countries, the entry of Ukraine into the European educational space, mobility of the labour market, high competition among specialists of various specialties, etc. Among the transport specialties, the most popular in recent years is the use of 275 Transport Technology (on the railway transport), which trains specialists in the field of transportation, logistics.

\section{Conclusions:}

To be able to compete in the global labor market, a specialist must become a professional in his business. This applies to all branches of the national economy. And this will be possible, given the acmeological approach when constructing a higher professional school.

Thus, the use of the ideas of the acmeological approach in vocational education will contribute to:

1. Modernization of higher professional education.

2. Development of the best qualities of each student, disclosure of his creative potential.

3. Improving the quality of higher professional education.

4. Formation of the image (prestige) of a specialty.

5. Formation of the image of the graduate (his self-realization, professional identity). 


\section{General conclusions}

1. Higher vocational education of the present must meet the demands of society, respond to all time requirements and challenges. To this end, the reform of higher professional education should be implemented; methodological approaches are the basis for its implementation (in our study competence, synergetic, acmeological).

2. In order to achieve better results in building a new higher vocational school, it is advisable to use the synthesis of the benefits of different approaches.

3. The competence approach in the system of higher vocational education performs the following functions: it is methodological, since it is prescribed in the Laws of Ukraine ("On Education", "On Higher Education", etc.); creates conditions for the approximation of the national education to the European one; designed to change the educational paradigm to one that meets the contemporary challenges of society; provides a reference point for education on the outcome.

4. Implementation of the synergetic approach to higher professional education: allows a new solution to the contradictions of today's pedagogical science, the key concepts of which are the following characteristics: constancy / variability, predictability / randomness, individual / collective, chaos / structuring, etc.; changes the educational vector for the unification of knowledge into the formation of a creative person; Provides new opportunities in the educational process (individual trajectories of development and self-development of all participants in the educational process); promotes the solution of didactic problems (compliance of the content of education with the requirements of time, selection of technological and methodological approaches, etc.).

5. Implementation of the acmeological approach in the system of higher vocational education will provide the following possibilities: modernization of higher professional education; development of the best qualities of each student, disclosure of his creative potential; improvement of the quality of higher professional education; formation of the image (prestige) of a specialty; formation of the image of the graduate (his self-realization, professional identity).

6. Our further research will be aimed at creating (constructing) a model of a modern graduate - a future specialist in the field of railway transport, competitive in the labour market, able to realize their best qualities and achieve a high level of professionalism. 


\section{References:}

1. Acmeology 2006. Methodological and methodological problems: ed. N.V. Kuzmina, L.I. Dubrovina. SPb: TsSi, 2006. 246 p.

2. Anisimov O.S. Acmeology and methodology: problems of psychotechnics and thought technics. Moscow, 1998. $772 \mathrm{p}$.

3. Bermus A.G. Problems and perspectives of the implementation of the competence approach in education//Eidos Internet Magazine. 2005. September 10th. URL: http://www.eidos.ru/journal/2005/0910-12.htm

4. Burgung I.V. The urgency of the introduction of the competence approach in educational practice // Actual problems of public administration, pedagogy and psychology: a collection of scientific works of the Kherson National Technical University. 2010. № 1 (2). P. 159-165.

5. Zhuk O.V. Belarus: Competence Approach in Pedagogical Preparation of University Students // Pedagogics. 2008. № 3. S. 99-105.

6. Winter I.A. Key competencies - a new paradigm of the result of education // Higher education today. 2003. № 5. P. 34-42.

7. Elahina L.V. Formation of a culture of professional activity of a future specialist on the basis of a competence approach (methodology, theory, practice): author's abstract. dis dock. ped Sciences: 13.00.08 "Theory and methodology of vocational education". Chelyabinsk, 2008. 55 p.

8. Kniazeva E.N. Bases of synergetics. Synergetic worldview. M.: LIBROKOM, 2010. $236 \mathrm{p}$.

9. Kniazeva E.N., Kurdiumov S.P. Synergetics: the nileenness of time and the co-evolutionary landscapes. M.: KomKniga, 2007. 272 p.

10. Kremin V.G., Ilyin V.V. Synergetics in education: the context of humancentricism: a monograph. [National Academy of Pedagogical Sciences of Ukraine]. K.: Pedagogical Thought, 2012. 368 p.

11. Kristopchuk T.Y. Competence approach: the European choice // Scientific Bulletin of Melitopol State Pedagogical University named after Bogdan Khmelnytsky. Series Pedagogy. 2011. № 6. P. 33-41.

12. Kuzmina N.V. Akmeologicheskaya theory of improving the quality of training of education specialists. M.: Research Center for Quality Problems of Specialists Training, 2001. $144 \mathrm{p}$.

13. Malanyuk N.M. Synergetics in vocational education (on the example of trainers of railway transport) // Pedagogics of the formation of a creative person in higher and secondary schools: SB. sciences etc. / [red. T.I. Suschenko (eds. ed.), etc.]. Zaporozhye: KPU, 2017. Vip. 56-57 (109-110). 660 s.

14. Malinetskyi G.G. Mathematical modeling of educational systems / Synergetic paradigm. Synergetics of education. M.: Progress-Tradition, 2007. P. 328-245.

15. Modernization of Ukraine's education in the context of European integration processes: historical and pedagogical aspect: Monograph / Avt. count O. Dubaseniuk, N.G. Sidorchuk, N.V. Yaks and others. / For the community Ed. N.G. Sidorchuk. Zhytomyr: In-ZHDU them. I. Franko, 2008. 300 p.

16. Continuous vocational education: problems, searches, prospects: Monograph / ed. I.A. Zyazyun. K.: Vispol, 2000. 636 pp. 


\section{Malaniuk Nataliia, Romanyshyna Ludmila}

17. Vocational pedagogical education: acme-synergetic approach: monograph / ed. O. Dubaseniuk. Zhytomyr: In-zdU them. I. Franka 2011. 389 c.

18. Equal J. Pedagogical testing: problems, delusions, perspectives: per. from english M.: Kogito Center, 1999. 144 p.

19. Romanyshyna L., Romanyshyna O., Ostrovska N. Methodological approaches to formation of professional identity of future teachers of humanitarian disciplines // Actual problems of public administration, pedagogy and psychology: collection sciences works of Kherson National Technical University. 2017. Issue 4. P. 97-100.

20. Seleuko G. Competencies and their classification // Popular education. 2004. № 4. P. 138-143.

21. Stelmakh Ya.G. Formation of professional mathematical competence of future engineers: author's abstract. diss ... Candidate in Ped. Sciences: 13.00.08. Volga State Social Scientist Acad. Samara, 2011.23 p.

22. Khodan O. Competence approach to the training of future specialists in higher educational institutions // Scientific Bulletin of Uzhgorod National University. Series: Pedagogy. Social work. 2013. P. 232-235.

23. Khutorskaya A.V. Key competencies as a component of a person-oriented education // Popular education. 2003. No. 2. S. 58-64.

24. Khutorskaya A.V. Methodology of person-oriented learning. How to train everyone in a different way?: manual for a teacher. M.: Publishing house VLADOS PRESS, 2005. 383 p.

25. Winterton J. Typology of knowledge, skills and competences: clarification of the concept and prototype [Text] / by J. Winterton, F. Delamare-Le Deist, E. Stringfellow. Cedefop, 2006. 131 p. 